\title{
Dendritic cells during Staphylococcus aureus infection: subsets and roles
}

Xuejie Wu and Feng $\mathrm{Xu}^{*}$

\begin{abstract}
Dendritic cells (DCs) are professional antigen-presenting cells (APCs) that play a crucial role in both innate and adaptive immune responses. DCs orient the immune responses by modulating the balance between protective immunity to pathogens and tolerance to self-antigens. Staphylococcus aureus (S. aureus) is a common member of human skin microbiota and can cause severe infections with significant morbidity and mortality. Protective immunity to pathogens by DCs is required for clearance of S. aureus. DCs sense the presence of the staphylococcal components using pattern recognition receptors (PRRs) and then orchestrate immune systems to resolve infections. This review summarizes the possible roles of DCs, in particular their Toll-like receptors (TLRs) involved in S. aureus infection and strategies by which the pathogen affects activation and function of DCs.
\end{abstract}

Keywords: Dendritic cells, Pattern recognition receptors, Toll-like receptors, Staphylococcus aureus

\section{Introduction}

Dendritic cells (DCs) were first identified by Steinman and colleagues in the early 1970s. The nomenclature was originally based on the cell s stellate shape and membranous processes [1]. DCs are now recognized as one of the most potent and efficient professional APCs within the immune system [2]. They have the unique capacity to prime nave $\mathrm{T}$ cell-mediated protective immune responses as well as maintain tolerance to self-antigens by controlling antigen presentation to T cells [3]. Upon antigen uptake and exposure to appropriate proinflammatory signals or cellular stress, DCs generally migrate from the tissue to secondary lymphoid organs and differentiate into mature DCs which are characterized by upregulation of major histocompatibility complex (MHC) class I and II, adhesins and costimulatory molecules. Here, they process and present captured antigens in the presence of the correct costimulatory molecules to initiate antigen-specific $\mathrm{T}$ and $\mathrm{B}$ cell immune responses $[4,5]$. DCs also participate in inducing and maintaining peripheral immune tolerance in the steady state, possibly through the induction of T-cell anergy or $\mathrm{T}$ regulatory cells (Tregs) via self-antigen presentation [6,7].

\footnotetext{
* Correspondence: xufeng99@yahoo.com

Department of Infectious Diseases, Second Affiliated Hospital, Zhejiang University School of Medicine, Hangzhou 310009, China
}

In the past decades, huge efforts have been made to explore the myriad immune functions of DCs after the pioneering work initiated by Steinman and colleagues. It is now well known that the DCs represent a heterogeneous cell population with distinctive functions and subsets [8]. Generally, human and mouse DCs can be grouped into at least two subsets, referred to as conventional DCs (cDCs) and plasmacytoid DCs (pDCs) based on differing morphological, phenotypic and functional specificity. cDCs can be further subdivided into two main subsets according to their phenotype, functional specialization, specific gene expression program and transcription factors [9-11]. These subdivisions correlate to the large and differing roles that DCs have on every aspect of the immune system, and will be described in detail below.

$S$. aureus is a common member of human skin microbiota and is well habituated to the human host $[12,13]$. This pathogen can cause infections of nearly all tissues and organs, and staphylococcal disease can vary in severity ranging from skin and soft tissue infections to necrotizing fasciitis, pneumonia, endocarditis, sepsis, and toxic shock syndrome. The high pathogenecity of $S$. aureus depends on its numerous tactics to evade immune system [14-17]. At present, infection of methicillin-resistant $S$. aureus (MRSA) which is resistant to most of the current available potent antibiotics poses a serious public health threat $[18,19]$. MRSA was previously confined to hospital settings 
where antibiotics have been used in abundance and the chance to make contact with this bacterium is very high [20]. However, community acquired MRSA (CA-MRSA) has emerged soon and gained much attention by clinicians and investigators [16,21].

DCs sense the presence of pathogens using pattern recognition receptors (PRRs), which recognize pathogen associated molecular patterns (PAMPs) expressed by various microorganisms. TLRs are the most well described PRRs [22]. To date, 13 different TLRs have been identified, 10 human TLRs (TLR1-10) and 12 mouse TLRs (TLR1-9, TLR11, TLR12, TLR13). TLR10 and TLR11-13 are specific to humans or mice respectively [23,24]. TLR $1,2,4-6$ and 11 are expressed at the cell surface while TLR 3 and 7-9 are located in the endosomal compartments [25]. It has recently been shown that TLR-driven early glycolytic reprogramming is essential for the anabolic demands of DC activation and function [26]. TLR expression varies according to DC subset. In humans, cDCs express TLR 1-8 and 10, and can be activated by various bacterial products $[27,28]$. Conversely, human and mouse pDCs express a restricted set of TLRs including TLR7 and TLR9 which sense viral RNA and DNA respectively [29,30]. Several TLRs have been implicated in the recognition of staphylococcal structures. For example, TLR2 is involved in the recognition of staphylococcal peptidoglycan, lipoteichoic acid (LTA) and staphylococcal enterotoxin B (SEB), while TLR4 can be activated by leukocidin (Luk), an exotoxin of $S$. aureus [31-34]. The differing TLRs of DC subsets and corresponding ligands are summarized in Table 1.

This review will focus on the possible roles of DCs and their well-equipped armamentarium, particularly TLRs in $S$. aureus infection, as well as the strategies utilized by $S$. aureus to evade DCs. Importantly, the findings summarized here may have implications for developing

Table 1 TLRs of DC subsets and corresponding ligands

\begin{tabular}{lll}
\hline DC subsets & TLR & ligands \\
\hline cDCs & $1 / 2$ & Triacyl lipoprotein \\
& 2 & Peptidoglycan, Lipoteichoic acid \\
3 & dsRNA \\
4 & Lipopolysaccharide \\
& 5 & Flagellin \\
& $6 / 2$ & Diacyl lipoprotein \\
& 7 & ssRNA \\
& 8 & ssRNA \\
& 10 & No ligand known \\
& 7 & ssRNA \\
PDCs & 9 & unmethylated CpG motifs of DNA \\
& 10 & No ligand known \\
\hline
\end{tabular}

Abbreviations: dsRNA, double-stranded RNA; ssRNA, single-stranded RNA. novel therapies aimed at improving DC function during $S$. aureus infection.

\section{Dendritic cell subsets and TLRs CDCs and their TLRs}

cDCs were initially thought to be of myeloid origin, based on their expression of the myeloid markers, such as CD13 and CD33 [35,36]. However, several studies have shown that $\mathrm{CDCs}$ may also originate from lymphoid precursor cells expressing Flt3 under the treatment of Flt3 ligand (Flt3L), a growth factor for hemopoietic progenitors [37-39]. Murine cDCs include both lymphoid organ-resident DCs and migratory DCs [40]. Considering the complexity of the $\mathrm{CDC}$ origin, most studies simply categorize murine $\mathrm{cDCs}$ as $\mathrm{CD} 11 \mathrm{~b}^{+}$or $\mathrm{CD} 8 \alpha^{+} / \mathrm{CD} 103^{+}$ cDCs. Here, $\mathrm{CD} 8 \alpha^{+}$DCs are demonstrated to be more efficient in the cross-presentation of exogenous antigens on MHC class I molecules [2,41]. In humans, cDCs can be further identified as $\mathrm{BDCA} 1^{+} \mathrm{DCs}$ and $\mathrm{BDCA} 3^{+} \mathrm{DCs}$ according to the characteristic surface expression of BDCA1 (CD1c) and BDCA3 (CD141) [42-44]. Human cDCs nearly express all TLRs except TLR9 $[28,29,45,46]$. Although cDCs do express TLR10, its ligands and functionality are still unknown [47]. Extracellular TLRs of cDCs such as TLR1, 2, 4-6 recognize cell wall components of bacteria and fungi. Lipopolysaccharide (LPS), a structurally diverse molecule, is a well-known ligand for TLR4 and the mechanisms involved in versatility of ligand recognition which is crucial for combating diverse microbial infection is unraveled by TLR4-MD-2-LPS structure [48]. TLR5 activation by flagellin is important for priming of the adaptive immune response in the intestine [49]. Except for direct recognition of the Gram positive bacteriaderived peptidoglycan [50], triacyl lipoprotein and diacyl lipoprotein can also be recognized by TLR2 through the formation of heterodimers with TLR1 or TLR6 respectively [22]. This exemplifies the complexity of TLRs and PAMPs recognition. After being activated by TLR ligands or agonists, cDCs secrete several cytokines important in immune responses, such as IL-6, IL-8, IL-10, IL-12 and TNF- $\alpha[22,51]$. Besides, cDCs also recognize nucleotidecontaining structures via intracellular TLRs. For example, TLR3 recognizes virus-derived double-stranded RNA (dsRNA) while TLR7 and TLR8 recognize single-stranded RNA (ssRNA) which comes from bacteria, virus or self $[22,52,53]$.

\section{pDCs and their TLRs}

Cell surface markers of human $\mathrm{pDCs}$ are characterized as $\mathrm{CD}^{+} \mathrm{CD} 45 \mathrm{RA}^{+} \mathrm{HLA}^{-D R^{+}} \mathrm{CD} 123{ }^{\text {high }} \mathrm{CD} 11 \mathrm{c}$-lineage-cells. pDCs do not express most of the myeloid antigens, such as CD11b, CD13, CD14, or CD33 and were suggested to be of lymphoid origin. Human pDCs express two additional markers, BDCA2 (CD303) and BDCA4 (CD304) 
$[39,54]$. It is now known that both human and mouse pDCs may also stem from myeloid precursors expressing Flt3 when stimulated with Flt3L $[37,38]$. Compared to cDCs, both human and mouse pDCs preferentially express high levels of TLR7 and TLR9 $[29,45]$. Although minimal expression of TLR1 on the pDCs has been reported by several studies, its biological function remains unclear $[29,47,55]$. More importantly, pDCs neither express TLR2, a heterodimeric partner for TLR1, nor respond to TLR1/ TLR2 ligands $[29,45,55,56]$. pDCs also express TLR10 which has been confirmed at both the mRNA and protein level $[47,55,57]$. However, the biological function and ligand of TLR10 have not been determined. pDCs preferentially secrete type I IFNs, especially IFN- $\alpha$ when TLR7 and TLR9 are triggered by ssRNA and unmethylated CpG motifs of DNA, respectively $[28,29,45,55,58]$.

Although DCs are rare subsets of cells among all blood mononuclear cells, they serve as a bridge linking innate and adaptive immune responses. Current data suggest that both $\mathrm{CDCs}$ and pDCs can be either myeloid or lymphoid origin. A developmental scheme for human $\mathrm{DC}$ lineages is shown in Figure 1.

\section{Virulence factors of $S$. aureus}

The whole genome of $S$. aureus encodes numerous toxins, mainly including pore-forming toxins, exfoliative toxins and superantigens [59]. The most common poreforming toxins are hemolysin- $\alpha$ (Hla, $\alpha$-toxin), leukotoxins and phenol-soluble modulins (PSMs) [60,61]. Hla is released by most $S$. aureus clinical isolates and spontaneously assembles into a heptameric pore in target cell membranes. It preferentially targets human lymphocytes and monocytes but not neutrophils [62,63]. Leukotoxins belong to a bicomponent family of cytotoxins consisting of one class $S$ and one class $F$ protein [64]. To date, five class F subunits (HlgB, LukF-PV, LukD, LukF-PV, and LukG) and six class $\mathrm{S}$ subunits (HlgA, HlgC, LukS-PV, LukE, LukM, and LukH) have been reported [60]. Leukotoxins can lyse monocytes, macrophages, and neutrophils via forming hetero-oligomeric pore complexes in target cell membranes $[65,66]$. PSMs, including the PSM $\alpha$ and PSM $\beta$ subfamilies are small, $\alpha$-helical amphipathic peptides which have multiple roles in staphylococcal virulence $[67,68]$.

Exfoliative toxins (ETs) A, B and D produced by $S$. aureus can efficiently cleave a single peptide bond in the extracellular region of human and mouse desmoglein 1 (Dsg1) [69]. The expression of ETs has been confirmed to be regulated by accessory gene regulator (agr) [70]. ETs are glutamate-specific serine proteases with high species specificity and responsible for staphylococcal scalded skin syndrome (SSSS), which predominantly affects infants and is characterized by the loss of superficial skin layers, dehydration, and secondary infections [71].

The staphylococcal superantigens (SAgs) are a family of potent immunostimulatory exotoxins. At present, 23

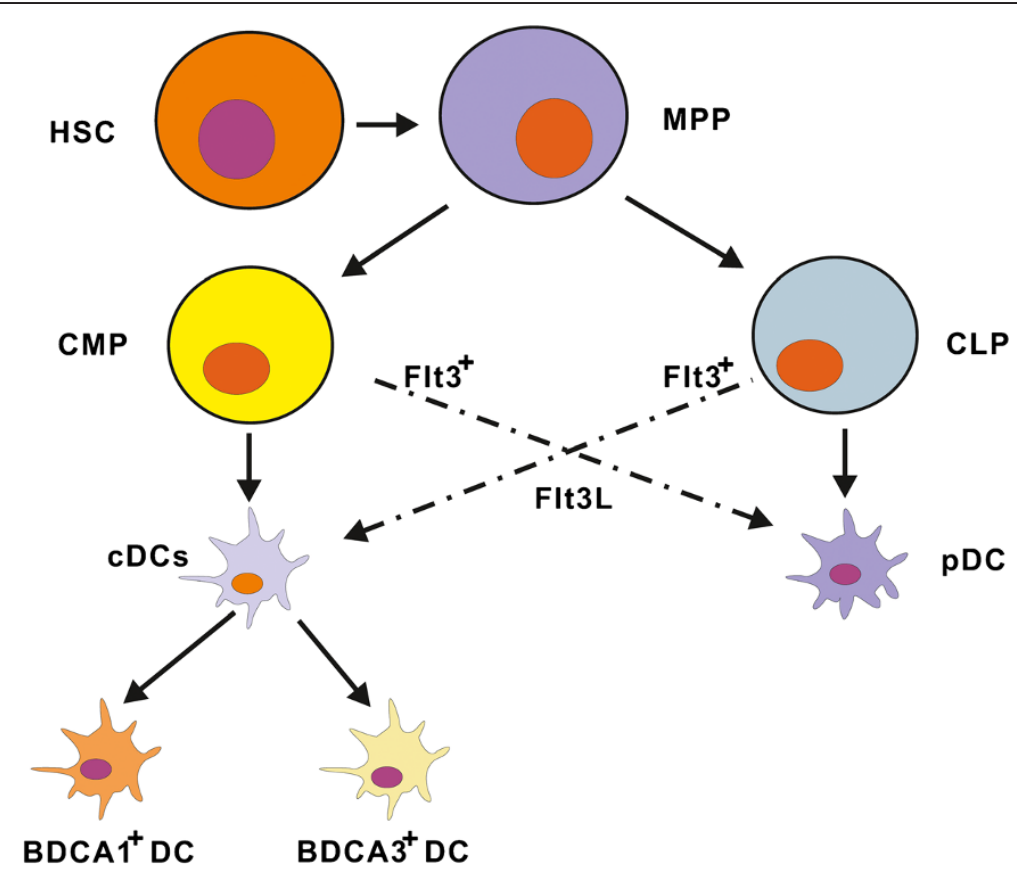

Figure $1 \mathrm{~A}$ developmental scheme for human DC lineages. Both CDCs and pDCs can originate from CMP and CLP lineages. Human CDCs are categorized as two main subsets including $B D C A 1^{+} D C s$ and $B D C A 3^{+} D C$. Abbreviations: HSC, hemopoietic stem cell; MPP, multipotent progenitors; CMP, common myeloid precursors; CLP, common lymphoid precursors. CDCs, conventional DCs; pDCs, plasmacytoid DCs. 
distinct staphylococcal SAgs have been characterized: the staphylococcal enterotoxins (SEs) A, B (multiple variant forms exist), $\mathrm{C}$ (multiple minor variant forms exist), $\mathrm{D}, \mathrm{E}$, and G; the staphylococcal enterotoxin-like toxins $\mathrm{H}, \mathrm{I}, \mathrm{J}, \mathrm{K}$, $\mathrm{L}, \mathrm{M}, \mathrm{N}, \mathrm{O}, \mathrm{P}, \mathrm{Q}, \mathrm{R}, \mathrm{S}, \mathrm{T}, \mathrm{U}, \mathrm{V}$, and $\mathrm{X}$ and toxic shock syndrome toxin-1 (TSST-1) [60,72,73]. Some of them can directly cross-link MHC class II molecules on APCs with T cell receptors to induce potent $\mathrm{T}$-cell activation and cytokine release $[74,75]$.

\section{Roles of different subsets of DCs in S. aureus infection}

DCs are more potent in presenting small amounts of microbial superantigens such as SEA [76], B, E and TSST-1, compared with monocytes or B cells. They also stimulate T cell proliferation far more efficiently than monocytes or B cells in the presence of SEA, SEB, SEE and TSST-1 [77], all of which bind well to MHC class II molecules [78-80]. After stimulation with the $S$. aureus Cowan strain I, both mouse and human DCs expressed IL-12 p40 and p35 mRNA. More importantly, they also produced IL-12p70 protein, a crucial factor for induction of Th1 immune response [81]. The $S$. aureus Cowan I strain, when cultured with epidermal DCs from the skin, also known as Langerhans cells (LCs), induced IL-6 (inflammatory cytokine), IL-12p40 (Th1 cytokine) production and inhibited TARC (Th2 cytokine) production by LCs [82]. When stimulated with SEB alone, DCs secreted abundant TNF- $\alpha$ and slight IL-12. However, IL-1 $\beta$ and IL-10 were undetectable in the culture medium. Concurrent with this process, DCs also expressed significantly higher HLA-DR and costimulatory molecules [83]. Although DCs do not kill S. aureus directly, depletion of DCs in CD11c- DTR transgenic mice resulted in increased bacterial loads in kidneys and lungs, higher mortality, more severe inflammatory injury and abolishment of IL-12 production. Nevertheless, adoptive transfer of either immature or LPS-matured bone marrow-derived DCs into normal BALB/c mice improved the capacity of these animals to eliminate $S$. aureus bacteria in the lungs. In addition, the impaired immunity of DC-depleted mice to $S$. aureus can be recovered by using exogenous recombinant mouse IL-12 [84]. These studies suggest that DCs preferentially induce Th1 immune response when encountered with $S$. aureus or SEs, probably through producing of IL-12, and then orchestrate innate and adaptive immune responses to fight against $S$. aureus infection.

In addition to SEs, DCs also react to other components derived from $S$. aureus. Leukocidin (Luk), an exotoxin of $S$. aureus is also capable of initiating the Th1-oriented immune response. Inden et al. demonstrated that LukF was the main mediator to induce IL-12p40 and TNF- $\alpha$ production in DCs in a dose-dependent fashion. Using a TLR4deficient mutant mouse model, IL-12p40 production of
DCs triggered by LukF was found to be controlled by TLR4 signaling [34]. In contrast to monocytes and monocyte-derived macrophages which preferentially prime modulatory IL-10 and weak IL-17 responses, monocyte-derived DCs were found to produce mainly IL-12 and IL-23, and initiate robust Th1/Th17 responses after staphylococcal peptidoglycan stimulation via TLR2 signaling [85,86]. Additionally, DCs can also be activated by lipoproteins of viable $S$. aureus through TLR2-MyD88 signaling and secret more IFN- $\gamma$ and IL-17 in CD4 ${ }^{+}$T cells to improve bacterial clearing and disease outcome [87].

However, DCs may also have a role in the worsening of atopic dermatitis (AD) inflammation caused by secondary $S$. aureus infection. Wash fluid from AD lesions with secondary $S$. aureus infection induced DCs to secrete proinflammatory cytokines including IL-1 $\beta$, IL-6, IL-10 and TNF- $\alpha$ in a MyD88-dependent manner. Production of these cytokines strongly correlated with wash fluidcontained lipoteichoic acid (LTA) which is a known microbial ligand derived from $S$. aureus for TLR2 activation $[88,89]$. Further study showed that staphylococcal LTA and muramyl dipeptide, the minimal structural unit of peptidoglycan with immunostimulating activity, synergistically induced maturation of human DCs and secretion of TNF- $\alpha$ and IL-12 p40 [90]. In order to unravel the roles of different DC subsets in $S$. aureus infection in detail, Jin and colleagues compared the differences of $\mathrm{CD}_{16}{ }^{+}$and $\mathrm{BDCA} 3^{+} \mathrm{DCs}, \mathrm{BDCA}^{+} \mathrm{DCs}$ treated with $S$. aureus. In contrast to $\mathrm{CD}_{1} 6^{+}$and $\mathrm{BDCA}^{+} \mathrm{DCs}^{+} \mathrm{BDCA}^{+} \mathrm{DCs}$ expressed high levels of TLR2 and scavenger receptor A (SR-A) which are required for recognition of $S$. aureus and subsequent activation of $\mathrm{BDCA}^{+}$DCs. Consistent with previous studies, BDCA $1^{+} \mathrm{DCs}$ engulfed $S$. aureus efficiently and then dramatically upregulated expression of surface markers, such as costimulatory molecules, MHC class I and II molecules. Moreover, $\mathrm{BDCA} 1^{+} \mathrm{DCs}$ also secreted abundant proinflammatory cytokines and promoted IFN- $\gamma$ production in CD4 and CD8 T cells [91]. These data indicate that DCs have a complicated role in $S$. aureus infection. It is appropriate to speculate that distinct subsets of DCs may fulfill different immune responses against $S$. aureus infection. These differences may explain the diverse outcomes of humans infected with S. aureus.

pDCs, in addition to their well established involvement in the viral immune response [39], also take part in host response to extracellular bacteria, including $S$. aureus. Parcina et al. showed that IFN- $\alpha$ production of $\mathrm{pDCs}$ triggered by $S$. aureus was independent of TLR2 and specific for coagulase-positive staphylococci. The specificity of the pDCs response to $S$. aureus was mediated by Ag-specific IgG and CD32. Blockade of TLR7/9 using inhibitory DNA oligonucleotides and chloroquine abrogated $S$. aureus-induced $\mathrm{pDC}$ activation, indicating 
the involvement of TLR7/9 by bacterial nucleic acids in this process [92]. It is reported that pDCs are located in tonsillar crypts and oro-nasopharyngeal epithelium, where they may encounter extracellular bacteria including colonized $S$. aureus. These pDCs do produce abundant IFN- $\alpha$, TNF- $\alpha$, IL-6 and show upregulated CD86 expression when activated by $S$. aureus [93]. However, some studies reported that $\mathrm{pDCs}$ alone are unresponsive to extracellular bacteria including $S$. aureus $[94,95]$. Further studies are needed to clarify the function of pDCs during $S$. aureus infection. Possible roles of DCs in S. aureus infection are illustrated in Figure 2.

\section{Strategies of S. aureus to affect DC function}

Skin sections treated with SEA or exfoliative toxin lead to significant depletion of LCs. Cholera and pertussis toxin-sensitive GTP-binding proteins were found to be involved in the LC depletion in response to SEA [96]. Muraille et al. demonstrated that APCs, a mixture of B cells, macrophages and DCs, obtained from mice injected 2 days earlier with SEB failed to stimulate an alloreactive in vitro response. In spite of an increase in spleen cellularity secondary to SEB injection, the absolute and relative number of DCs was significantly decreased upon SEB-treatment. However, no significant reduction was observed in splenic $B$ cells and cells expressing a typical macrophage phenotype [97]. Further study showed that DCs activated by SEB secreted high levels of IL-2 but no IL-12p70 and drove polarization of nave $\mathrm{T}$ cells into the Th2 subset. Using the TLR2 stably transfected human embryonic kidney (HEK) 293 cells and anti-TLR2 antibodies, the signaling involved in this process was demonstrated to be triggered by the SEBTLR2 interaction [32]. SEB also promoted the expression of $\mathrm{T}$ cell immunoglobulin mucin domain (TIM) 4 in human DCs. TIM4 expressed-DCs preferentially induced Th2 responses through the interaction of TIM4 and TIM1 [98].

Phenol-soluble modulin (PSM) peptide toxins are strongly expressed in CA-MRSA and exert their function on DCs through interacting with the formyl peptide receptor (FPR)2. During infection, PSMs, a virulence factor of CA-MRSA, attracted DCs through interaction with FPR2. PSMs treated-DCs showed impaired clathrinmediated endocytosis and reduced secretion of the proinflammatory cytokines such as TNF, IL-12 and IL-6 while increased IL-10 secretion. The IL-10 producingDCs inhibited T-cell activation and T-cell priming towards Th1 cells. Furthermore, they also induced IL-10 producing Tregs in vitro [99]. In turn, Tregs can also provide DCs with immune regulatory activity in mice unresponsive to SEB through IFN- $\gamma$-independent CD152-mediated activation of tryptophan catabolism [100]. These results suggest that $S$. aureus can also direct DCs to induce Th2 and Treg cell responses but inhibit Th1 responses in certain

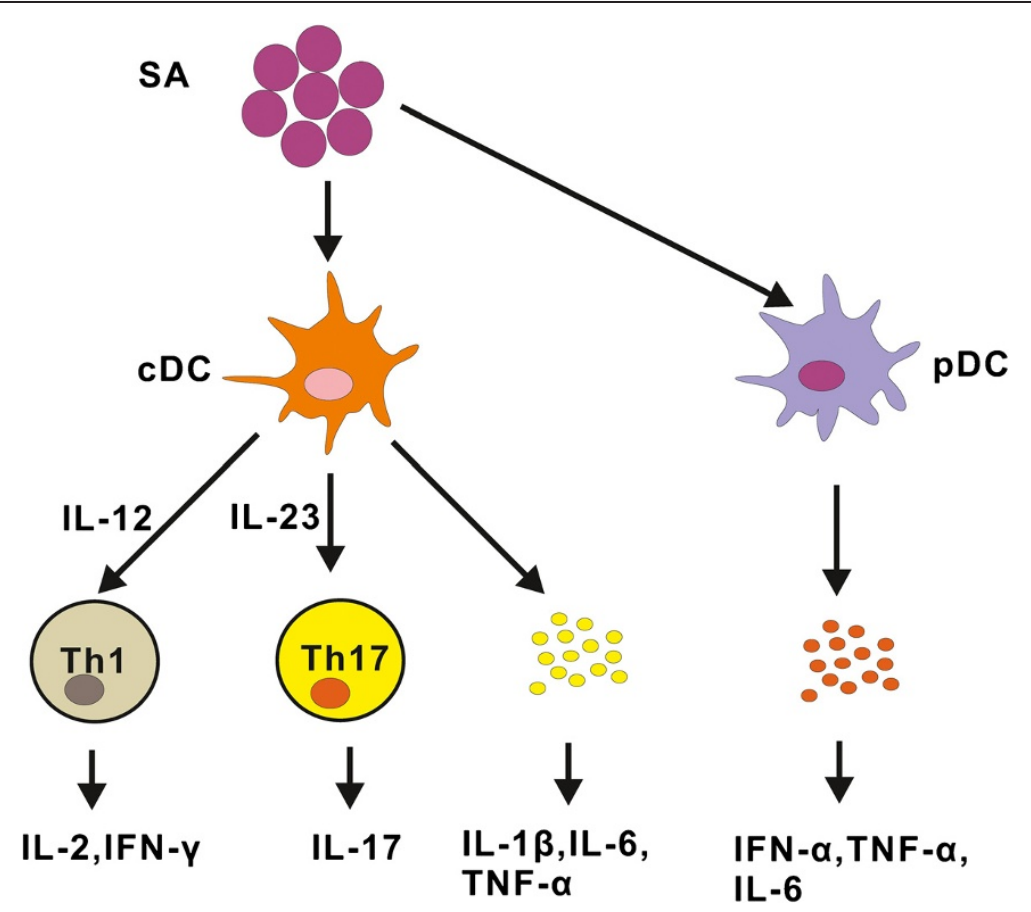

Figure 2 Possible roles of DCs in S. aureus infection. S. aureus triggered DCs (CDCs and pDCs) secret a variety of cytokines which are vital in inducing protective immune responses against S.aureus as well as promoting inflammation. Th1, Th17 cells and cytokines produced by these effector cells are involved in this process. Abbreviations: SA, S. aureus. 


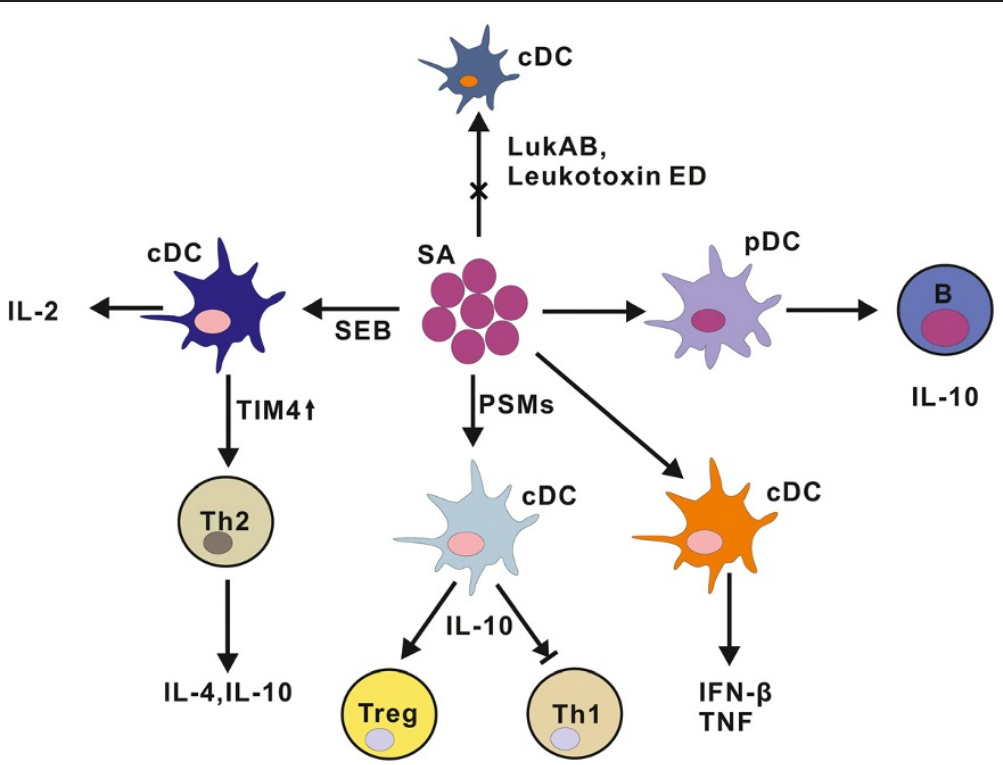

Figure 3 Possible strategies of S. aureus to affect DCs function. Several components of S. aureus may affect DCs function. Possible tactics used by S. aureus include killing DC directly, inhibiting Th1 responses, inducing Th2 and Treg responses as well as IL-10-producing B cells. Abbreviations: SEB, S. aureus enterotoxin B; TIM4, T cell immunoglobulin mucin domain (TIM) 4; LukAB, leukocidin AVB; PSMs, Phenol-soluble modulin; spA-SA, surface protein A-bearing S. aureus.

conditions. However, the accurate mechanisms of DCs to initiate different immune responses have not been determined currently.

Apart from its effect on DC function, S. aureus can also directly kill DCs to avoid immune clearance. Dumont et al. demonstrated that a novel styphylococcal cytotoxin denoted leukocidin A/B (LukAB) was responsible for cytotoxicity towards monoctye-derived DCs. Although LukA and LukB alone have little effect on cell viability, a combination of the purified recombinant LukA and LukB potently kills DCs [65]. Additionally, CCR5, a well-known HIV coreceptor has also been confirmed as a receptor for the $S$. aureus leukotoxin ED. Through its interaction with CCR5, leukotoxin ED selectively kills $\mathrm{CCR}^{+} \mathrm{T}$ lymphocytes and myeloid cells including monocyte-derived DCs in a CCR5-dependent manner [101].

In vitro studies showed that bone marrow derived DCs of $\mathrm{TLR}^{-/}$mice produced significantly decreased IFN- $\beta$ levels after incubation with S. aureus USA300 for 20 hours, compared to wildtype mice. However, TLR9 ${ }^{-1-}$ mice exerted enhanced clearance of $S$. aureus from the airways and lung tissue. Further analysis indicated that TNF may be related to the control of $S$. aureus infection because its level in BALF was reduced significantly in infected TLR9 ${ }^{-1}$ while the other proinflammatory cytokines including IL-17, CXCL-10, KC, IL-6, and IFN- $\gamma$ were unchanged, compared to controls [102]. This is consistent with the detrimental effect of TNF signaling on S. aureus pulmonary infection [103]. Parcina and colleagues showed that human pDCs activated by surface protein A-bearing $S$. aureus were involved in TLR9 signaling and mediated B cell proliferation and Ig production. Cooperation of pDCs and B cells enhanced B cell-derived IL-10 production of which was partially dependent on TLR2-active lipoproteins, a hallmark of the Staphylococcus species [104]. These results indicate that S. aureus may exploit pDCs and their TLRs to establish B cell-mediated immune tolerance to facilitate infection. Possible strategies of $S$. aureus to affect DCs function are delineated in Figure 3.

\section{Summary}

DCs are vital mediators in both innate and adaptive immune responses. During infection, DCs sense various pathogens through distinct PRRs and orchestrate different immune arms to defend against invading pathogens. However, pathogens such as S. aureus have also evolved tactics to evade immune clearance by impairing activation and function of DCs. It is important to further illuminate the role of differing subsets of DCs upon $S$. aureus infection, which may be instrumental in developing new therapeutic strategies for S. aureus infection, especially the MRSA infection.

\section{Abbreviations}

DCs: Dendritic cells; APCs: Antigen-presenting cells; PRRs: Pattern recognition receptors; TLRs: Toll-like receptors; PAMPs: Pathogen associated molecular patterns; MHC: Major histocompatibility complex; MRSA: Methicillin-resistant S. aureus; CA-MRSA: Community-acquired MRSA; SEs: Staphylococcal enterotoxins; TSST: Toxic shock syndrome toxin-1; ETs: Exfoliative toxins; SR-A: Scavenger receptor A; LCs: Langerhans cells. 


\section{Competing interests}

The authors declare that there are no competing interests regarding the publication of this article.

\section{Authors' contribution}

XJ W created the tables and figures and drafted the primary manuscript. F X designed and corrected the manuscript. Both authors have read and approved the final manuscript.

\section{Acknowledgement}

This study was supported by grants from the National Natural Science Foundation of China (81400621, 81370176), Ministry of Education of China (NCET-12-0484), Natural Science Foundation of Zhejiang Province (LR12H01003), and Health Department of Zhejiang Province (201342966).

Received: 10 October 2014 Accepted: 10 December 2014 Published online: 18 December 2014

\section{References}

1. Steinman RM, Cohn ZA: Identification of a novel cell type in peripheral lymphoid organs of mice. I. Morphology, quantitation, tissue distribution. J Exp Med 1973, 137(5):1142 1162.

2. Joffre OP, Segura E, Savina A, Amigorena S: Cross-presentation by dendritic cells. Nat Rev Immunol 2012, 12(8):557 569.

3. Morelli AE, Thomson AW: Tolerogenic dendritic cells and the quest for transplant tolerance. Nat Rev Immunol 2007, 7(8):610 621.

4. Banchereau J, Steinman RM: Dendritic cells and the control of immunity. Nature 1998, 392(6673):245 252.

5. Steinman RM, Banchereau J: Taking dendritic cells into medicine. Nature 2007, 449(7161):419 426

6. Yamazaki S, Iyoda T, Tarbell K, Olson K, Velinzon K, Inaba K, Steinman RM: Direct expansion of functional CD25+CD4+ regulatory $T$ cells by antigen-processing dendritic cells. J Exp Med 2003, 198(2):235 247

7. Yamazaki S, Morita A: Dendritic cells in the periphery control antigen-specific natural and induced regulatory T cells. Front Immunol 2013, 4:151.

8. Guilliams M, Ginhoux F, Jakubzick C, Naik SH, Onai N, Schraml BU, Segura E, Tussiwand R, Yona S: Dendritic cells, monocytes and macrophages: a unified nomenclature based on ontogeny. Nat Rev Immunol 2014, 14(8):571 578

9. Dalod M, Chelbi R, Malissen B, Lawrence T: Dendritic cell maturation: functional specialization through signaling specificity and transcriptional programming. EMBO J 2014, 33(10):1104 1116.

10. Guilliams M, Henri S, Tamoutounour S, Ardouin L, Schwartz-Cornil I, Dalod $M$, Malissen B: From skin dendritic cells to a simplified classification of human and mouse dendritic cell subsets. Eur J Immunol 2010, 40(8):2089 2094.

11. Steinman RM: Decisions about dendritic cells: past, present, and future. Annu Rev Immunol 2012, 30:1 22

12. Murillo N, Raoult D: Skin microbiota: overview and role in the skin diseases acne vulgaris and rosacea. Future Microbiol 2013, 8(2):209 222

13. Xu F, Diao R, Liu J, Kang Y, Wang X, Shi L: Curcumin attenuates staphylococcus aureus-induced acute lung injury. Clin Respir J 2014, Jan 24. doi: $10.1111 /$ crj.12113.

14. Spaan AN, Surewaard BG, Nijland R, van Strijp JA: Neutrophils versus Staphylococcus aureus: a biological tug of war. Annu Rev Microbiol 2013, 67:629 650.

15. Foster TJ: Immune evasion by staphylococci. Nat Rev Microbio/ 2005, 3(12):948 958

16. Graves SF, Kobayashi SD, DeLeo FR: Community-associated methicillinresistant Staphylococcus aureus immune evasion and virulence. J Mol Med (Berl) 2010, 88(2):109 114

17. Xu F, Kang Y, Zhang H, Piao Z, Yin H, Diao R, Xia J, Shi L: Akt1-mediated regulation of macrophage polarization in a murine model of Staphylococcus aureus pulmonary infection. J Infect Dis 2013, 208(3):528 538

18. Rodvold KA, McConeghy KW: Methicillin-resistant Staphylococcus aureus therapy: past, present, and future. Clin Infect Dis 2014, 58(Suppl 1):S20 27.

19. Li M, Du X, Villaruz AE, Diep BA, Wang D, Song Y, Tian Y, Hu J, Yu F, Lu Y, Otto M: MRSA epidemic linked to a quickly spreading colonization and virulence determinant. Nat Med 2012, 18(5):816-819.
20. Lin MY, Hayden MK: Methicillin-resistant Staphylococcus aureus and vancomycin-resistant enterococcus: recognition and prevention in intensive care units. Crit Care Med 2010, 38(8 Suppl):S335 344.

21. Boucher H, Miller LG, Razonable RR: Serious infections caused by methicillin-resistant Staphylococcus aureus. Clin Infect Dis 2010, 51(Suppl 2):S183 197.

22. Takeuchi O, Akira S: Pattern recognition receptors and inflammation. Cell 2010, 140(6):805 820

23. West AP, Koblansky AA, Ghosh S: Recognition and signaling by toll-like receptors. Annu Rev Cell Dev Biol 2006, 22:409 437.

24. O'Neill LA, Golenbock D, Bowie AG: The history of Toll-like receptors redefining innate immunity. Nat Rev Immunol 2013, 13(6):453 460.

25. Kawai T, Akira S: TLR signaling. Semin Immunol 2007, 19(1):24 32.

26. Everts B, Amiel E, Huang SC, Smith AM, Chang CH, Lam WY, Redmann V, Freitas TC, Blagih J, van der Windt GJ, Artyomov MN1, Jones RG, Pearce EL, Pearce EJ1: TLR-driven early glycolytic reprogramming via the kinases TBK1-IKKvarepsilon supports the anabolic demands of dendritic cell activation. Nat Immunol 2014, 15(4):323-332.

27. Zanoni I, Granucci F: Regulation of antigen uptake, migration, and lifespan of dendritic cell by Toll-like receptors. J Mol Med (Berl) 2010, 88(9):873 880

28. Ito T, Amakawa R, Kaisho T, Hemmi H, Tajima K, Uehira K, Ozaki Y, Tomizawa $H$, Akira S, Fukuhara S: Interferon-alpha and interleukin-12 are induced differentially by Toll-like receptor 7 ligands in human blood dendritic cell subsets. J Exp Med 2002, 195(11):1507 1512

29. Kadowaki N, Ho S, Antonenko S, Malefyt RW, Kastelein RA, Bazan F, Liu YJ: Subsets of human dendritic cell precursors express different toll-like receptors and respond to different microbial antigens. J Exp Med 2001, 194(6):863 869.

30. Bao M, Liu YJ: Regulation of TLR7/9 signaling in plasmacytoid dendritic cells. Protein Cell 2013, 4(1):40 52.

31. Takeda K, Kaisho T, Akira S: Toll-like receptors. Annu Rev Immunol 2003, 21:335 376

32. Mandron M, Aries MF, Brehm RD, Tranter HS, Acharya KR, Charveron M, Davrinche C: Human dendritic cells conditioned with Staphylococcus aureus enterotoxin B promote $\mathrm{TH} 2$ cell polarization. J Allergy Clin Immunol 2006, 117(5):1141 1147.

33. Fournier B, Philpott DJ: Recognition of Staphylococcus aureus by the innate immune system. Clin Microbiol Rev 2005, 18(3):521 540.

34. Inden $K$, Kaneko J, Miyazato A, Yamamoto N, Mouri S, Shibuya Y, Nakamura K, Aoyagi T, Hatta M, Kunishima H, Hirakata Y, Itoh Y, Kaku M, Kawakami K: Toll-like receptor 4-dependent activation of myeloid dendritic cells by leukocidin of Staphylococcus aureus. Microbes Infect 2009, 11(2):245-253.

35. Ito $T$, Inaba M, Inaba K, Toki J, Sogo S, Iguchi T, Adachi Y, Yamaguchi K, Amakawa R, Valladeau J, Saeland S, Fukuhara S, Ikehara S: A CD1a+/CD11c+ subset of human blood dendritic cells is a direct precursor of Langerhans cells. J Immunol 1999, 163(3):1409-1419.

36. Traver D, Akashi K, Manz M, Merad M, Miyamoto T, Engleman EG, Weissman IL: Development of CD8alpha-positive dendritic cells from a common myeloid progenitor. Science 2000, 290(5499):2152 2154.

37. D'Amico A, Wu L: The early progenitors of mouse dendritic cells and plasmacytoid predendritic cells are within the bone marrow hemopoietic precursors expressing Flt3. J Exp Med 2003, 198(2):293 303

38. Karsunky H, Merad M, Cozzio A, Weissman IL, Manz MG: Flt3 ligand regulates dendritic cell development from Flt3+ lymphoid and myeloid-committed progenitors to Flt3+ dendritic cells in vivo. J Exp Med 2003, 198(2):305 313.

39. Wu L, Liu YJ: Development of dendritic-cell lineages. Immunity 2007 26(6):741 750

40. Heath WR, Carbone FR: Dendritic cell subsets in primary and secondary T cell responses at body surfaces. Nat Immunol 2009, 10(12):1237 1244.

41. Mildner A, Jung S: Development and function of dendritic cell subsets. Immunity 2014, 40(5):642 656

42. Reizis B: Classical dendritic cells as a unique immune cell lineage. J Exp Med 2012, 209(6):1053 1056.

43. Schreibelt G, Klinkenberg LJ, Cruz LJ, Tacken PJ, Tel J, Kreutz M, Adema GJ, Brown GD, Figdor CG, de Vries IJ: The C-type lectin receptor CLEC9A mediates antigen uptake and (cross-)presentation by human blood BDCA3+ myeloid dendritic cells. Blood 2012, 119(10):2284 2292.

44. Breece E, Paciotti B, Nordahl CW, Ozonoff S, Van de Water JA, Rogers SJ, Amaral D, Ashwood P: Myeloid dendritic cells frequencies are increased 
in children with autism spectrum disorder and associated with amygdala volume and repetitive behaviors. Brain Behav Immun 2013, 31:69 75

45. Jarrossay D, Napolitani G, Colonna M, Sallusto F, Lanzavecchia A Specialization and complementarity in microbial molecule recognition by human myeloid and plasmacytoid dendritic cells. Eur J Immunol 2001, 31(11):3388 3393.

46. Poulin LF, Salio M, Griessinger $E$, Anjos-Afonso F, Craciun L, Chen JL, Keller AM, Joffre O, Zelenay S, Nye E, Le Moine A, Faure F, Donckier V, Sancho D, Cerundolo V, Bonnet D, Reis e Sousa C: Characterization of human DNGR-1+ BDCA3+ leukocytes as putative equivalents of mouse CD8alpha+ dendritic cells. J Exp Med 2010, 207(6):1261-1271.

47. Flacher V, Bouschbacher M, Verronese E, Massacrier C, Sisirak V, Berthier-Vergnes O, de Saint-Vis B, Caux C, Dezutter-Dambuyant C, Lebecque S, Valladeau J: Human Langerhans cells express a specific TLR profile and differentially respond to viruses and Gram-positive bacteria. J Immunol 2006, 177(11):7959-7967.

48. Park BS, Song DH, Kim HM, Choi BS, Lee H, Lee JO: The structural basis of lipopolysaccharide recognition by the TLR4-MD-2 complex. Nature 2009 458(7242):1191 1195

49. Uematsu S, Fujimoto $K$, Jang MH, Yang BG, Jung YJ, Nishiyama M, Sato S, Tsujimura T, Yamamoto M, Yokota Y, Kiyono H, Miyasaka M, Ishii KJ, Akira S: Regulation of humoral and cellular gut immunity by lamina propria dendritic cells expressing Toll-like receptor 5. Nat Immunol 2008, 9(7):769-776.

50. Meng Y, Chen C, Wang L, Wang X, Tian C, Du J, Li HH: Toll-like receptor-2 ligand peptidoglycan upregulates expression and ubiquitin ligase activity of CHIP through JNK pathway. Cell Physiol Biochem 2013, 32(4):1097 1105

51. Schreibelt G, Tel J, Sliepen KH, Benitez-Ribas D, Figdor CG, Adema GJ, de Vries IJ: Toll-like receptor expression and function in human dendritic cell subsets: implications for dendritic cell-based anti-cancer immunotherapy. Cancer Immunol Immunother 2010, 59(10):1573 1582

52. Kariko K, Buckstein M, Ni H, Weissman D: Suppression of RNA recognition by Toll-like receptors: the impact of nucleoside modification and the evolutionary origin of RNA. Immunity 2005, 23(2):165 175.

53. Cheng YS, Xu F: Anticancer function of polyinosinic-polycytidylic acid. Cancer Biol Ther 2010, 10(12):1219 1223.

54. Corcoran L, Ferrero I, Vremec D, Lucas K, Waithman J, O'Keeffe M, Wu L, Wilson A, Shortman K: The lymphoid past of mouse plasmacytoid cells and thymic dendritic cells. J Immunol 2003, 170(10):4926 4932

55. Krug A, Towarowski A, Britsch S, Rothenfusser S, Hornung V, Bals R, Giese T, Engelmann H, Endres S, Krieg AM, Hartmann G: Toll-like receptor expression reveals CpG DNA as a unique microbial stimulus for plasmacytoid dendritic cells which synergizes with CD40 ligand to induce high amounts of IL-12. Eur J Immunol 2001, 31(10):3026-3037.

56. Matsumoto M, Funami K, Tanabe M, Oshiumi H, Shingai M, Seto Y, Yamamoto A, Seya T: Subcellular localization of Toll-like receptor 3 in human dendritic cells. J Immunol 2003, 171(6):3154 3162

57. Hasan U, Chaffois C, Gaillard C, Saulnier V, Merck E, Tancredi S, Guiet C, Briere F, Vlach J, Lebecque S, Trinchieri G, Bates EE: Human TLR10 is a functional receptor, expressed by $B$ cells and plasmacytoid dendritic cells, which activates gene transcription through MyD88. J Immunol 2005, 174(5):2942-2950

58. Hornung V, Rothenfusser S, Britsch S, Krug A, Jahrsdorfer B, Giese T, Endres S, Hartmann G: Quantitative expression of toll-like receptor 1-10 mRNA in cellular subsets of human peripheral blood mononuclear cells and sensitivity to CpG oligodeoxynucleotides. J Immunol 2002, 168(9):4531 4537.

59. Otto M: Staphylococcus aureus toxins. Curr Opin Microbiol 2014, 17:32 37

60. Grumann D, Nubel U, Broker BM: Staphylococcus aureus toxins their functions and genetics. Infect Genet Evol 2014, 21:583 592

61. DuMont AL, Torres VJ: Cell targeting by the Staphylococcus aureus pore-forming toxins: it's not just about lipids. Trends Microbio/ 2014, 22(1):21 27.

62. Bhakdi S, Muhly M, Korom S, Hugo F: Release of interleukin-1 beta associated with potent cytocidal action of staphylococcal alpha-toxin on human monocytes. Infect Immun 1989, 57(11):3512 3519.

63. Valeva A, Walev I, Pinkernell M, Walker B, Bayley H, Palmer M, Bhakdi S: Transmembrane beta-barrel of staphylococcal alpha-toxin forms in sensitive but not in resistant cells. Proc Natl Acad Sci U S A 1997, 94(21):11607 11611

64. Kaneko J, Kamio Y: Bacterial two-component and hetero-heptameric pore-forming cytolytic toxins: structures, pore-forming mechanism, and organization of the genes. Biosci Biotechnol Biochem 2004, 68(5):981 1003
65. Dumont AL, Nygaard TK, Watkins RL, Smith A, Kozhaya L, Kreiswirth BN, Shopsin B, Unutmaz D, Voyich JM, Torres VJ: Characterization of a new cytotoxin that contributes to Staphylococcus aureus pathogenesis. Mol Microbiol 2011, 79(3):814 825

66. Ventura CL, Malachowa N, Hammer CH, Nardone GA, Robinson MA, Kobayashi SD, DeLeo FR: Identification of a novel Staphylococcus aureus two-component leukotoxin using cell surface proteomics. PLoS One 2010, 5(7):e11634.

67. Rautenberg $M$, Joo HS, Otto M, Peschel A: Neutrophil responses to staphylococcal pathogens and commensals via the formyl peptide receptor 2 relates to phenol-soluble modulin release and virulence. FASEB J 2011, 25(4):1254 1263.

68. Cheung GY, Kretschmer D, Duong AC, Yeh AJ, Ho TV, Chen Y, Joo HS, Kreiswirth BN, Peschel A, Otto M: Production of an attenuated phenol-soluble modulin variant unique to the MRSA clonal complex 30 increases severity of bloodstream infection. PLoS Pathog 2014, 10(8):e1004298.

69. Nishifuji K, Sugai M, Amagai M: Staphylococcal exfoliative toxins: "molecular scissors" of bacteria that attack the cutaneous defense barrier in mammals. J Dermatol Sci 2008, 49(1):21 31

70. Sheehan BJ, Foster TJ, Dorman CJ, Park S, Stewart GS: Osmotic and growth-phase dependent regulation of the eta gene of Staphylococcus aureus: a role for DNA supercoiling. Mol Gen Genet 1992, 232(1):49 57

71. Bukowski M, Wladyka B, Dubin G: Exfoliative toxins of Staphylococcus aureus. Toxins (Basel) 2010, 2(5):1148 1165.

72. Xu SX, McCormick JK: Staphylococcal superantigens in colonization and disease. Front Cell Infect Microbiol 2012, 2:52

73. Salgado-Pabon W, Case-Cook LC, Schlievert PM: Molecular analysis of staphylococcal superantigens. Methods Mol Biol 2014, 1085:169 185.

74. Holtfreter S, Broker BM: Staphylococcal superantigens: do they play a role in sepsis? Arch Immunol Ther Exp (Warsz) 2005, 53(1):13 27

75. Langley R, Patel D, Jackson N, Clow F, Fraser JD: Staphylococcal superantigen super-domains in immune evasion. Crit Rev Immunol 2010, 30(2):149 165

76. Bhardwaj N, Young JW, Nisanian AJ, Baggers J, Steinman RM: Small amounts of superantigen, when presented on dendritic cells, are sufficient to initiate T cell responses. J Exp Med 1993, 178(2):633 642.

77. Bhardwaj N, Friedman SM, Cole BC, Nisanian AJ: Dendritic cells are potent antigen-presenting cells for microbial superantigens. J Exp Med 1992, 175(1):267 273.

78. Karp DR, Long EO: Identification of HLA-DR1 beta chain residues critical for binding staphylococcal enterotoxins A and E. J Exp Med 1992, 175(2):415 424

79. Mollick JA, Chintagumpala M, Cook RG, Rich RR: Staphylococcal exotoxin activation of T cells. Role of exotoxin-MHC class II binding affinity and class II isotype. J Immunol 1991, 146(2):463 468

80. Mollick JA, Cook RG, Rich RR: Class II MHC molecules are specific receptors for staphylococcus enterotoxin A. Science 1989, 244(4906):817 820

81. Heufler C, Koch F, Stanzl U, Topar G, Wysocka M, Trinchieri G, Enk A, Steinman RM, Romani N, Schuler G: Interleukin-12 is produced by dendritic cells and mediates T helper 1 development as well as interferon-gamma production by T helper 1 cells. Eur J Immunol 1996, 26(3):659 668

82. Mitsui H, Watanabe $T$, Saeki H, Mori K, Fujita H, Tada Y, Asahina A, Nakamura K, Tamaki K: Differential expression and function of Toll-like receptors in Langerhans cells: comparison with splenic dendritic cells. J Invest Dermatol 2004, 122(1):95 102

83. Coutant KD, de Fraissinette $A B$, Cordier A, Ulrich P: Modulation of the activity of human monocyte-derived dendritic cells by chemical haptens, a metal allergen, and a staphylococcal superantigen. Toxicol Sci 1999, 52(2):189 198

84. Schindler D, Gutierrez MG, Beineke A, Rauter Y, Rohde M, Foster S, Goldmann O, Medina E: Dendritic cells are central coordinators of the host immune response to Staphylococcus aureus bloodstream infection. Am J Pathol 2012, 181(4):1327 1337

85. Frodermann V, Chau TA, Sayedyahossein S, Toth JM, Heinrichs DE, Madrenas $\mathrm{J}$ : A modulatory interleukin-10 response to staphylococcal peptidoglycan prevents Th1/Th17 adaptive immunity to Staphylococcus aureus. J Infect Dis 2011, 204(2):253 262.

86. Salvi V, Scutera S, Rossi S, Zucca M, Alessandria M, Greco D, Bosisio D, Sozzani S, Musso T: Dual regulation of osteopontin production by TLR stimulation in dendritic cells. J Leukoc Biol 2013, 94(1):147 158.

87. Schmaler M, Jann NJ, Ferracin F, Landmann R: T and B cells are not required for clearing Staphylococcus aureus in systemic infection 
despite a strong TLR2-MyD88-dependent T cell activation. J Immunol 2011, 186(1):443 452.

88. Voorhees T, Chang J, Yao Y, Kaplan MH, Chang CH, Travers JB: Dendritic cells produce inflammatory cytokines in response to bacterial products from Staphylococcus aureus-infected atopic dermatitis lesions. Cell Immunol 2011, 267(1):17 22.

89. Michelsen KS, Aicher A, Mohaupt M, Hartung T, Dimmeler S, Kirschning CJ, Schumann RR: The role of toll-like receptors (TLRs) in bacteria-induced maturation of murine dendritic cells (DCS). Peptidoglycan and lipoteichoic acid are inducers of DC maturation and require TLR2. J Biol Chem 2001, 276(28):25680 25686.

90. Kim HJ, Yang JS, Woo SS, Kim SK, Yun CH, Kim KK, Han SH: Lipoteichoic acid and muramyl dipeptide synergistically induce maturation of human dendritic cells and concurrent expression of proinflammatory cytokines. J Leukoc Biol 2007, 81(4):983989.

91. Jin JO, Zhang W, Du JY, Yu Q: BDCA1-Positive Dendritic Cells (DCs) Represent a Unique Human Myeloid DC Subset That Induces Innate and Adaptive Immune Responses to Staphylococcus aureus Infection. Infect Immun 2014, 82(11):4466 4476

92. Parcina M, Wendt C, Goetz F, Zawatzky R, Zahringer U, Heeg K, Bekeredjian-Ding I: Staphylococcus aureus-induced plasmacytoid dendritic cell activation is based on an IgG-mediated memory response. J Immunol 2008, 181(6):3823 3833.

93. Michea P, Vargas P, Donnadieu MH, Rosemblatt M, Bono MR, Dumenil G, Soumelis V: Epithelial control of the human $\mathrm{pDC}$ response to extracellular bacteria. Eur J Immunol 2013, 43(5):1264 1273.

94. Piccioli D, Sammicheli C, Tavarini S, Nuti S, Frigimelica E, Manetti AG, Nuccitelli A, Aprea S, Valentini S, Borgogni E, Wack A, Valiante NM: Human plasmacytoid dendritic cells are unresponsive to bacterial stimulation and require a novel type of cooperation with myeloid dendritic cells for maturation. Blood 2009, 113(18):4232-4239.

95. Poth JM, Coch C, Busch N, Boehm O, Schlee M, Janke M, Zillinger T, Schildgen O, Barchet W, Hartmann G: Monocyte-mediated inhibition of TLR9-dependent IFN-alpha induction in plasmacytoid dendritic cells questions bacterial DNA as the active ingredient of bacterial lysates. J Immunol 2010, 185(12):7367 7373 .

96. Pickard S, Shankar G, Burnham K: Langerhans' cell depletion by staphylococcal superantigens. Immunology 1994, 83(4):568 572.

97. Muraille E, De Smedt T, Andris F, Pajak B, Armant M, Urbain J, Moser M, Leo $O$ : Staphylococcal enterotoxin B induces an early and transient state of immunosuppression characterized by $\mathrm{V}$ beta-unrestricted $\mathrm{T}$ cell unresponsiveness and defective antigen-presenting cell functions. J Immunol 1997, 158(6):2638 2647.

98. Liu T, He SH, Zheng PY, Zhang TY, Wang BQ, Yang PC: Staphylococcal enterotoxin B increases TIM4 expression in human dendritic cells that drives naive CD4 T cells to differentiate into Th2 cells. Mol Immunol 2007, 44(14):3580 3587.

99. Schreiner J, Kretschmer D, Klenk J, Otto M, Buhring HJ, Stevanovic S, Wang JM, Beer-Hammer S, Peschel A, Autenrieth SE: Staphylococcus aureus phenol-soluble modulin peptides modulate dendritic cell functions and increase in vitro priming of regulatory T cells. J Immunol 2013, 190(7):3417 3426.

100. Feunou P, Vanwetswinkel S, Gaudray F, Goldman M, Matthys P, Braun MY: Foxp3 $+\mathrm{CD} 25+\mathrm{T}$ regulatory cells stimulate IFN-gamma-independent CD152-mediated activation of tryptophan catabolism that provides dendritic cells with immune regulatory activity in mice unresponsive to staphylococcal enterotoxin B. J Immunol 2007, 179(2):910 917.

101. Alonzo F 3rd, Kozhaya L, Rawlings SA, Reyes-Robles T, DuMont AL, Myszka DG, Landau NR, Unutmaz D, Torres VJ: CCR5 is a receptor for Staphylococcus aureus leukotoxin ED. Nature 2013, 493(7430):51 55.

102. Parker D, Prince A: Staphylococcus aureus induces type I IFN signaling in dendritic cells via TLR9. J Immunol 2012, 189(8):4040 4046.
103. Gomez MI, Lee A, Reddy B, Muir A, Soong G, Pitt A, Cheung A, Prince A: Staphylococcus aureus protein $A$ induces airway epithelial inflammatory responses by activating TNFR1. Nat Med 2004, 10(8):842 848.

104. Parcina M, Miranda-Garcia MA, Durlanik S, Ziegler S, Over B, Georg P, Foermer S, Ammann S, Hilmi D, Weber KJ, Schiller M, Heeg K, Schneider-Brachert W, Gtz F, Bekeredjian-Ding I: Pathogen-triggered activation of plasmacytoid dendritic cells induces IL-10-producing B cells in response to Staphylococcus aureus. I Immunol 2013, 190(4):1591-1602.

doi:10.1186/s12967-014-0358-z

Cite this article as: Wu and Xu: Dendritic cells during Staphylococcus aureus infection: subsets and roles. Journal of Translational Medicine 2014 12:358.

\section{Submit your next manuscript to BioMed Central and take full advantage of:}

هConvenient online submission

$\otimes$ Thorough peer review

$\nabla$ No space constraints or color $\nabla$ gure charges

$\otimes I m m e d i a t e$ publication on acceptance

Q Inclusion in PubMed, CAS, Scopus and Google Scholar

$\otimes$ Research which is freely available for redistribution

Submit your manuscript at www.biomedcentral.com/submit
C Biomed Central 